Elsevier required licence: (C) <2018>. This manuscript version is made available under the CC-BY-NCND 4.0 license http://creativecommons.org/licenses/by-nc-nd/4.0/

The definitive publisher version is available online at

[https://www.sciencedirect.com/science/article/pii/S1750583616309331?via\%3Dihub] 
Understanding key elements in establishing a social license for CCS: an empirical approach

Clair Gough*, Rebecca Cunningham ${ }^{1}$, Sarah Mander

Tyndall Centre for Climate Change Research, University of Manchester, Manchester M13 4PL, clair.gough@manchester.ac.uk

Tel: $+44(0) 1613063447$

Fax: $+44(0) 1613063723$

Sarah.mander@manchester.ac.uk

Tel: +44(0)1613063259

Fax: $+44(0) 1613063723$

\footnotetext{
1 Present address: University of Technology Sydney, Institute for Sustainable Futures, Broadway, Ultimo, 2007 Australia
} 


\title{
Understanding key elements in establishing a social license for CCS: an empirical approach
}

Clair Gough*, Rebecca Cunningham², Sarah Mander

Tyndall Centre for Climate Change Research, University of Manchester, Manchester M13 4PL, clair.gough@manchester.ac.uk

\begin{abstract}
This paper presents results of empirical research with the broad aim of exploring societal responses to $\mathrm{CO}_{2}$ storage, framed around the concept of social license to operate (SLO). We describe a mixed method approach incorporating stakeholder interviews and focus groups deployed in two case study locations in the UK. The approach helps us to build up an understanding of the social context in which Carbon Capture and Storage (CCS) will be introduced, in terms of the specific local conditions and with reference to the influence of local experiences of other technologies (such as hydraulic fracturing (fracking), for example). This understanding is then used to guide further empirical research, from which we assess the extent to which an SLO for CCS is emerging. Results show that perceptions of trust and confidence in key institutions to safely manage projects are highly dependent not just on the track record of the organisations but are strongly influenced by past experiences with different technologies. While the indications for achieving an SLO for CCS are currently positive, consolidating and maintaining that support depends on the evolving social, industrial and political landscape.
\end{abstract}

\section{Keywords}

$\mathrm{CO}_{2}$ storage; public perceptions; focus group; stakeholder interviews; fracking

\footnotetext{
2 Present address: University of Technology Sydney, Institute for Sustainable Futures, Broadway, Ultimo, 2007 Australia
} 


\section{Introduction}

Carbon Capture and Storage (CCS) remains a key pillar in climate change mitigation strategies for reaching the climate change goals outlined in the 2015 Paris agreement (UNFCCC, 2015). Demonstration of the technology at a commercial scale is crucial if its potential is to be realised (Reiner, 2016) - whether its role is in abating $\mathrm{CO}_{2}$ emissions from fossil fuel power generation, enabling abatement of large scale process industry emissions or as a part of a negative emissions strategy using biomass energy with CCS. This paper presents results of empirical research with the broad aim of exploring societal responses to $\mathrm{CO}_{2}$ storage and to the monitoring of reservoirs. The research was conducted as part of the DiSECCS (Diagnostic seismic toolbox for the efficient control of $\mathrm{CO}_{2}$ storage) project, an interdisciplinary collaboration investigating monitoring approaches and developing techniques to better understand $\mathrm{CO}_{2}$ storage processes. Other partners to the DiSECCS project are investigating modelling and monitoring methods for offshore storage using a variety of techniques referenced against data from a selection of ongoing storage projects (see e.g. Falcon-Suarez et al. 2014; Papageorgiou and Chapman 2015; Jenkins et al. 2015). The broad aim of the social research component, described below, was to understand the wider social context in which the scientific monitoring takes place.

The specific research objectives addressed in this paper are:

1. to explore the wider social context for $\mathrm{CO}_{2}$ storage in the UK;

2. to assess potential social responses to subsurface injection and site monitoring approaches;

3. to identify significant factors in establishing a social license in the context of CCS and in particular offshore $\mathrm{CO}_{2}$ storage in the UK.

We address these objectives using a mixed method approach incorporating stakeholder interviews and focus groups undertaken in two case study locations in northern England. The case studies were selected to map social responses in two areas which had respectively: i) recently experienced high profile planning applications for a new energy development (hydraulic fracturing, 'fracking', for shale gas exploration), but no CCS proposals ${ }^{3}$ (Lancashire) and ii) CCS development activity which was seeking to establish an industrial CCS cluster (supported by an industrial consortium with some initial government funding ${ }^{4}$ ), but where fracking was unlikely to be pursued in the near term (Teesside). Hydraulic fracturing for shale gas exploration was chosen as a potentially analogous technology from which lessons could be learnt for $\mathrm{CO}_{2}$ storage because of comparable operational processes within the subsurface (drilling, injection and monitoring) and a link to fossil energy use (Herzog and Wolff, 2014) and the potential for common issues to be raised in this context, notably in the light of induced seismic events in the first case study area in 2011 (DECC, 2014; Pater and Baisch, 2011). We refer to the fracking analogue in order to explore what influence, if any, recent controversies might have on social responses to $\mathrm{CO}_{2}$ storage and whether anything can be learnt that might inform the implementation of $\mathrm{CO}_{2}$ storage.

Previous research has looked at social responses to CCS technology as a mitigation technology (see for example, L'Orange Seigo et al., 2014; Oltra et al., 2010; Upham and Roberts, 2011) and to specific

3 http://www.lancashire.gov.uk/council/planning/major-planning-applications/shale-gas-developments-inlancashire.aspx [accessed 1st july 2016]

${ }^{4}$ http://www.teessidecollective.co.uk/ [accessed 1 August 2016 ] 
aspects of CCS (e.g. Gough et al., 2014; Itaoka et al., 2013; Mabon et al., 2014a; Wallquist et al., 2012). In terms of social responses to CCS, it can be useful to consider its three key components, namely capture, transport and storage, separately; each is associated with different processes and, potentially, different host communities, particularly if storage and capture sites are not located in close proximity. In European contexts, the geological storage of $\mathrm{CO}_{2}$ is arguably the most novel aspect of the CCS chain; it has also been shown to be a primary focus of concern amongst members of the lay public (Eurobarometer, 2011; Feenstra et al., 2010; Mander et al., 2010). In other oil and gas producing regions, however, notably in North America, where $\mathrm{CO}_{2}$ injection is commonplace (for enhanced oil recovery) it is less likely to be viewed as such a novel approach.

Few studies have specifically focused on perceptions of geological storage of $\mathrm{CO}_{2}$. One study, which looked at social responses at five onshore storage sites in Europe, demonstrated the importance of non-technical factors in site selection, with outcomes highly dependent on local and temporal contingencies (Oltra et al., 2012). Furthermore, the existence of a trusting relationship between communities and developers, and the actions of other stakeholders (such as NGOs, local policy makers, media etc) which may influence trust between parties, were found to be critical to a project's success (Oltra et al., 2012; Terwel et al., 2011) and how the relative risks and benefits of the technology are perceived (Midden and Huijts, 2009; Yang et al., 2016). Although the majority of these case studies related to onshore storage contexts, early empirical research suggests that offshore storage, as is proposed in the UK, is not necessarily likely to be more readily accepted (Mabon et al., 2014b; Mabon et al., 2014a). Furthermore, while perceived techno-scientific risks of CCS are important, they are not the only factor in public and stakeholder assessments of geological storage (Mabon et al., 2013).

We have framed our research around the social license to operate (SLO) concept, which we explain in Section 2, setting out some of the key elements relevant to understanding the social license. Batel et al (2013) reflect on a need to consider social responses to low energy infrastructure in ways that go beyond 'acceptance of' or 'support for' a particular technology, recognising complexities in the relationships between communities and technologies. Key to this is an understanding of the wider social context in which a technology is to be deployed (Ashworth et al., 2012; Bradbury et al., 2009). Here we describe an empirical approach in which we unpack the social context and local conditions relevant to a proposed CCS project and which we contrast with experiences relating to the more wellknown technology of hydraulic fracturing for shale gas extraction. The empirical work was conducted in three stages, which we present separately; in Section 3 we describe how semi-structured stakeholder interviews were conducted to scope the social context in each of our case study locations and in Section 4 we describe Focus Groups with members of the public in the two sites, with the aim of building a more in-depth understanding of an emerging social license for $\mathrm{CO}_{2}$ storage in the UK. A further element of the work, a social network analysis, was also conducted in the two case study regions but is not described I the present paper (further information may be found in Mander et al., 2017). Discussion and Conclusions are presented in Sections 5 and 6 respectively.

\section{Elements of a social licence}

The term social licence to operate (SLO) originated in the late 1990s within the context of the mining industry, to conceptualise relationships between community and industry (Dowd and James, 2014) but is now becoming more widely used in other sectors (Hall et al., 2015; Moffat et al., 2015) particularly as human rights and environmental issues become more prominent in debates around 
controversial industries (Raman and Mohr, 2014). With this wider application comes a move away from a primarily corporate focus as the concept is increasingly becoming the subject of academic and theoretical research (see Moffat et al. 2015).

A SLO can be broadly defined as informal permission given by the local community and broader society to industry to pursue technical work (Thomson and Boutilier 2011 quoted in (Dowd and James, 2014)). The meaning and use of the term has been found to vary across different industries (Hall et al., 2015) with a variety of interpretations covering acceptance, desire, beneficial relationships or mutual benefit, and lack of opposition (Dowd and James, 2014). In the context of Shale Gas, notably in North America where there has been a rapid expansion in hydraulic fracturing activities, studies have identified factors which have contributed to a problematic SLO. For instance a historical lack of trust with the industries involved has be found to present a barrier to establishing engagement (Smith and Richards, 2015); this disconnect between stakeholders and communities combined with issues of transparency and lack of enforcement of regulations have been identified as making it particularly challenging to build a SLO (House 2013). An analysis of the print media has also highlighted how concerns and issues vary between regions and over time, suggesting that policies and strategies must be adapted to the specific time and context, stressing the importance of cultural and social concerns in addition to technical or economic risks (Gehman et al., 2016). There has been very little consideration of the SLO concept for shale gas or fracking in the UK; comparing responses in North America and the UK, Whitton (2017) found that despite quite different governance contexts, the limited opportunity for the public to influence decisions in both regions, poor social justice and procedural fairness has limited the potential to establish and SLO in both places.

However, the SLO concept is yet to become widely established within the context of CCS, the limited applications to date relate to projects or studies in Australia. Steeper (2013) discusses the community consultation processes that were conducted for the first operational CCS project in Australia (the CO2CRC Otway Project) which he considers to be central to achieving the social license for the project at that time. Furthermore, Hall et al. (2015) interviewed stakeholders to compare the use of the SLO concept in relation to four energy technologies, including CCS. They found that compared to wind energy and mining, the immature CCS and geothermal industries lacked a history of engagement from which to build a SLO; although the concept is gaining usage with respect to CCS, stakeholders framed the process in terms of tolerance of the technology rather than acceptance. The application of the SLO concept at this early stage may be hindered by a lack of public awareness or understanding of CCS technology, which may be interpreted as the presence or absence of a social licence (Dowd and James, 2014). Given the limited experience and awareness of CCS technology amongst the wider public, any SLO for CCS remains highly provisional and, hence, fragile (Dowd and James, 2014). In this context we argue that it is important to explore what factors might impact an emerging SLO, drawing lessons where possible from analogous technologies, in this case hydraulic fracturing for shale gas. We approach this research by considering some of the key features of SLO, and what takes it beyond a simple state of 'public acceptance' of a technology.

\subsection{The importance of scale}

The SLO may be considered across multiple geographical scales, its strength being that it can reference a variety of communities around a project - not just local residents (Syn 2014). This allows 
consideration of the views not only of host communities but also those of communities of interest which may be at the local project level as well as national (or even international) level and, potentially, SLO may be achieved at one scale but not at another (Parsons and Moffat, 2014). Where a particular project has no local community as such, the local SLO becomes indistinguishable from, or "reverts" to, a national SLO (Dowd and James, 2014). The notion that SLO may vary in strength and quality indicates the possibility for different levels of license intensities, or a "continuum of support" (Hall et al., 2015), which may range from absence or removal of an SLO up to a sense of "co-ownership" between community and industry, for example (Dowd and James, 2014; Hall et al., 2015).

\subsection{Stakeholder relationships}

The essential characteristic of the SLO is based on partnerships between communities, operators and government and is thus dependent on a variety of factors that contribute to building trust between the stakeholders. Although the term license suggests parallels with legal approval, SLO is not a formal or legal license and fundamentally differs from its legal counterparts. Community disapproval or opposition can strongly impact on the viability of a project and can be a critical condition for a project's success and, in this sense, can signify communities' empowerment to withdraw approval and prevent a project proceeding (Syn, 2014). Furthermore, achieving an SLO may potentially drive projects to go beyond minimum legal compliance (Raman and Mohr, 2014).

As communities weigh up the relative costs and benefits of a technology, they are implicitly engaging in a form of social exchange; if the technology is perceived to bring a net benefit it is more likely be viewed positively (Zhang and Moffat 2015). However, in communities with high levels of poverty there is the risk that developments may be more readily accepted if negative impacts are downplayed in favour of potential benefits that they may bring (Zhang and Moffatt 2015). This introduces notions of justice and of particular relevance here are procedural and environmental justice. Procedural justice relates to the fairness of processes through which decisions are made (Shrader-Frechette, 2002) and depend in part on how consultation processes are managed and providing genuine opportunities for communities to participate or influence decisions. Environmental justice, is a concept, originally used in the United States in the 1980s in relation to toxic or hazardous waste and the distribution of environmental harm (Schlosberg, 2013). Its use has since extended to wider concerns of equity and the protection of minority or marginalised individuals or communities (human and non-human) against environmental disadvantage (Schlosberg, 2013). Inequitable processes and outcomes in terms of siting decisions and social exchange are likely to have negative impacts on the formation of a SLO within local host communities and beyond.

\subsection{Social license as a dynamic condition}

A social license is, by it's a nature, a dynamic condition and not a static one-off approval; it depends on a process of maintaining relations and dialogue through which 'socio-political legitimacy' is established (Dowd and James, 2014), rather than being an end state (e.g. social acceptance). This makes it both intangible and contestable (Moffat et al., 2015; Parsons and Moffat, 2014) such that the strength and quality of a project's social license may change over time as attitudes and opinions evolve 
(Dowd et al., 2015) and the influences and relationships that govern its stability change (Hall et al., 2015). Because a project has not been rejected by a community does not mean that it has secured a social license to operate (Syn, 2014); maintaining ongoing functional community relations is key. Thus, while a legal license is something that may be formally issued to an operator, the status of a social license is a more informal and fluid notion, dependent on the "values, perceptions and expectations of a wide variety of stakeholders" (Moffat et al., 2015).

\section{4 $\underline{\text { Trust, risk and confidence }}$}

While there are many definitions of risk, in the context of the concerns of lay publics, what is important is uncertainty about potential future negative or unwanted events rather than more technical notions that relate to probabilities and magnitudes of outcomes (Joffe, 2003). 'Institutional based trust', which is based on a view of 'competence, integrity and benevolence' (Bachmann and Inkpen, 2011) may be involved in establishing a technology and is particularly important when an issue is difficult to manage or understand by an individual. As such, trust becomes a significant factor in both the perception and acceptability of associated risks, particularly in situations associated with controversy (Poortinga and Pidgeon, 2005; Slovic, 1993). Furthermore it is suggested that the relation between trust and risk is strongly influenced by certain contextual factors including the significance of the subject and an individual's familiarity with it (Earle and Siegrist, 2008). The formation of trust is grounded in the characteristics of the organisations involved and the wider context in which a technology is situated. Thus risk perceptions, trust and confidence in government and industry to operate and regulate a project are inherently related and are crucial to establishing a social license to operate; a belief that the competence and integrity is in place to manage risks and act in the interest of communities is essential (Moffat and Zhang, 2014).

Establishing trust between stakeholders is a long term process dependent on the interactions of a variety of factors including current and past associations which govern knowledge and confidence between stakeholders, their reliability and predictability, and expectations of how the industry will operate (Moffat et al., 2015). Part of this complex arrangement is the role of scientists, scientific evidence and technical expertise and how this information is translated and communicated. While scientific evidence alone is likely to be insufficient for achieving public acceptability (Dowd et al., 2015), it is nevertheless a major factor. Various studies have explored how information on CCS and its potential risks can influence people's concern about the technology (Upham and Roberts, 2011; Wallquist et al., 2010) indicating that how data and evidence about geological storage is presented and discussed should be considered carefully.

\section{Scoping the social context}

\subsection{Methodology}

The empirical research described in this paper was focused around two case study locations: the county of Lancashire, in northwest England, and the Teesside area, in north east England. The county of Lancashire has an area of 2,903 $\mathrm{km}^{2}$ with a population of 1,191,700 and larger proportions of the population than the national average employed in sectors such as wholesale, retail, education, manufacturing, health and social work (Lancashire County Council, 2011; 2016a). The Tees Valley 
(Teesside) Combined Authority covers an area of $1,562 \mathrm{~km}^{2}$ with a population of 660,000 (TVCA, 2016). Employment in the Tees Valley has relatively higher numbers employed in manufacturing, construction and utilities compared to the national average, with high concentrations of key sectors such as advanced manufacturing and process industries; it hosts $58 \%$ of the UK's chemical industry (Tees Valley Unlimited, 2016). Our initial scoping of the two regions was conducted through an analysis of print media reporting (not presented here) and a series of semi-structured interviews with stakeholders. The interviews explored issues around both CCS, with a focus on $\mathrm{CO}_{2}$ storage, and hydraulic fracturing for shale gas. Semi-structured interviews were selected in this instance as they allow for common ground to be covered for each interview, while allowing participants the opportunity to discuss particular pertinent issues in more depth (Fontana and Frey, 2000). In each instance, interviewees were asked similar questions about both CCS and fracking, covering awareness of the technology and its impact on the local areas, arguments in favour and against the technology, siting decisions, information sources and sharing, influence of campaigning groups and community engagement. Twelve interviews were conducted either face to face or over the phone and took place between July and September 2015. Interview times varied from 40-90 minutes and each interviewee agreed for the interview to be recorded.

The procedure for recruitment was mirrored at each site. In the first instance, a web search was performed to identify a variety of key professional stakeholders, who were invited to participate via email, followed up with a phone call. In the first case study region, recruitment was focused around the town of Blackpool in the county of Lancashire in the north west of England, close to the location of two earthquakes triggered by nearby fracking (DECC, 2014; Pater and Baisch, 2011). At this stage, despite approaching over 20 individuals and organisations in the Blackpool area, we were unable to identify anyone willing or available to be interviewed. The timing of recruitment coincided with the decision on an application from Cuadrilla to Lancashire County Council for licenses to commence exploratory drilling for shale gas in the nearby town of Preston; this application was extremely controversial locally and although permission was denied due to noise and traffic concerns, the prospect of an appeal remained (Lancashire County Council, 2016b) ${ }^{5}$. In the light of this, and given that our research was not primarily concerned with fracking or shale gas, we followed up some of the invitations to understand better why there was a reluctance to participate in the research interviews. Despite there being no official embargoes on discussing the subject from any of the organisations contacted, we found that stakeholders in the area simply did not want to talk about the technology, such was the level of controversy associated with its development within the area. At this point we concentrated on completing interviews in the second case study area (Teesside, in north east England), before returning to the first case study area, extending the recruitment further throughout the county of Lancashire, but again with limited success in recruitment. Table 1 shows the distribution of completed stakeholder interviews. Note that, in addition to the regional stakeholders, representatives from two national level local government organisations were also interviewed; these organisations provide support and coordination for Local Authorities in a variety of areas, including technology deployment, and were identified as relevant stakeholders during the regional interviews. These organisations have been listed as national stakeholders in Table 1.

\footnotetext{
${ }^{5}$ Since completing this research, the appeal from Cuadrilla was upheld by the Communities Secretary at one of the two sites under consideration in the area; a decision on the second site is pending.
} 
Our research interest here is primarily in relation to $\mathrm{CO}_{2}$ storage and monitoring, and the conditions necessary to achieve a social license to operate. It was thus considered useful to include the results of the three interviews in Lancashire for the valuable qualitative evidence bringing specific perspectives on proposed applications for hydraulic fracturing for shale gas. Analysed alongside the interviews in Teesside and the focus group data from both regions, the contextual information provided by these interviews adds further depth to support our understanding of how people experience technologies which use the subsurface (Hay, 2010). As noted previously, all interviewees were asked the same questions about both technologies, although in Lancashire interviews focused first on fracking before moving on to $\mathrm{CO}_{2}$ storage and CCS, and vice versa in Teesside.

\begin{tabular}{lccc} 
& Teesside & Lancashire & National \\
\hline $\begin{array}{l}\text { Local Government } \\
\text { (elected representative) }\end{array}$ & 1 & 1 & \\
\hline National Government (MP) & 1 & \\
\hline $\begin{array}{l}\text { European Government } \\
\text { (MEP) }\end{array}$ & 1 & \\
\hline Industry & 2 & \\
\hline NGO & 2 & \\
\hline $\begin{array}{l}\text { Quasi-NGO } \\
\text { (local Government umbrella } \\
\text { groups) }\end{array}$ & & \\
\hline Academic & & \\
\end{tabular}

Table 1. Stakeholders interviewed in case study regions

\section{$3.2 \underline{\text { Results }}$}

Following a brief overview of the stakeholders' views of the two technologies, here we consider their responses in the context of the features of SLO identified in Section 2, relating responses to the influence of scale, the role of different communities of stakeholders, the influence of previous experience with a technology, and issues of trust and confidence in key institutions and organisations.

CCS was viewed very positively by all of the stakeholders interviewed in the Teesside region; it was seen as presenting an opportunity for the area, primarily on the grounds of bringing or maintaining jobs but also it was seen as strengthening the prospects for maintaining industry in the area. There was a strong sense of pride in technical expertise in Teesside and CCS was regarded as a way of further developing transferable skills, of enhancing the region's competitiveness and retaining and attracting investment - it was seen as a 'win-win' technology in terms of contributing to both the climate change agenda and the local economy. Interviewees were asked about potential negative as well as the positive impacts of the technology - while some struggled to identify negatives, one of the NGOs questioned the costs of the technology and who would pay for it. One of the elected representatives and the national stakeholders considered that the public might be sceptical about the technology and another elected representative raised concerns about leakage; however, all of the interviewees were broadly positive about the potential deployment of the technology in the region. 
Interviews with Lancashire stakeholders focused on fracking with more limited discussion of CCS, due to the primary interest and knowledge about the former in relation to the region. However, the scepticism associated with fracking was not voiced in relation to CCS by any of the interviewees in this region; CCS was also viewed in a broadly positive light by these stakeholders, the only concern, raised by an academic, related to any possible local impacts or leakage risks. One stakeholder questioned whether the technology was linked to coal seam gas exploration in the North West as there was the possibility for a planning application for pilot exploration in the region.

Focusing on shale gas, dissonance between different scales of governance, between different areas of policy and the impact this can have on stakeholder relationships emerged as themes across many of the stakeholder interviews. In Lancashire, a local government representative identified strong top down pressure to pursue shale gas as a component of wider energy policy, although, as one of the academics stated, the exploitation of new fossil fuel reserves was at odds with the UK maintaining a credible position in relation to climate change. At a local scale, central government was felt to be 'bullying' local councils, in an attempt to push through national energy policy through deployment of a technology that local communities did not want; the local government representative highlighted the challenge in balancing roles as a community's representative in the town hall and the council representative in the community. The two national representatives of local government umbrella organisations also both commented on the top down imposition of decisions in the context of shale gas, calling for decisions to be more decentralised. However, the elected local government representative in Lancashire noted that the anti-fracking voices were heard more loudly than those pro-fracking in the region, aware that although some business leaders were supportive they were not widely heard - a view also voiced by one of the academics that those in support of fracking tend to keep quiet.

Issues of risk, trust and confidence in regulatory processes and key institutions were clearly significant across both technologies and sites. The shortcomings of the planning and regulatory system were identified across the interviews; based on established regimes overseeing the oil and gas industry, the regulatory processes for offshore projects, such as $\mathrm{CO}_{2}$ storage, were deemed to be better established, and hence more straight forward, than those for onshore fracking for which the lack of a single regulatory body was identified as a limitation. The current (onshore) planning system was described by one interviewee as combative, with the approaches to communication about planning notices (for example adverts in local press) resulting in poor dissemination.

There was a clear contrast in how interviewees talked about the two technologies, with CCS widely seen as a less risky, even less novel, more "proven" approach than fracking, which was described as being more uncertain, particularly with respect to the potential for pollution of groundwater. In Teesside, interviewees were more comfortable discussing CCS than fracking, reflecting their more limited professional experience with the latter and the lower potential for its deployment within their region. Some possible beneficiaries in the region were identified should a shale gas industry develop, these included the chemicals industry, or the linking of CCS with shale gas that could make it more favourable (with the caveat that it could be extracted safely). While there was a high level of confidence expressed by all stakeholders in Teesside in the industry's ability to manage CCS, the industrial stakeholders were alone in their trust in industry to safely implement fracking. The long history of pioneering industry in the Teesside region was repeatedly cited as grounds for trust in the companies involved - the professional stakeholders in Teesside all considered that their confidence in 
local industries to manage risks, look after their workers and "do things properly" was shared by the local communities. One of the NGOs in Teesside, for example, expressed his confidence that CCS "will work", because it had been done before, confident in industrial and scientific experience in Teesside - sentiments he did not hold with respect to fracking, expressing a distrust in companies' ability to "self monitor", driven by short term profit. A clear sense of pride in the region's success in improving heavily polluted and industrialised area was also voiced by several of the stakeholders.

Furthermore, the local government representatives (from both local and national bodies) appeared confident that local government was trusted to act in the interest of their local communities in the face of demands from national government. The erosion of trust in the national government amongst these stakeholders in the context of fracking however, does not appear to have carried over to CCS, for which national government remained a trusted source of information. While identifying the economic and employment benefits as arguments in favour of shale gas there was scepticism about the potential for shale gas to deliver these benefits.

Both regional and national stakeholders expressed a keen awareness that technologies may become tarnished by high profile controversy, which may have a long term impact on perceptions of the technology. Although many of the Teesside interviewees were personally comfortable with hydraulic fracturing as a technique they recognised the high potential for public opposition to fracking and the high emotions it inspired. The two national local government stakeholders also referred to the level of shale gas controversy in the context that they would be reluctant to initiate information or dissemination events on the topic, something that they would normally do. CCS was certainly seen by all as a much less controversial approach.

In summary, certain key themes emerged during the stakeholder interviews which we further unpacked within the focus groups. Firstly, the broadly positive views of CCS viewed as beneficial to the region, particularly in terms of economic investment and jobs (Teesside) and the openness to consider CCS, despite sharp awareness of widely held hostility towards shale gas developments (Lancashire). We were particularly keen to explore whether the confidence in the industry, especially in Teesside, to safely manage CCS technology, and pride in the technical expertise developed within the region, was shared amongst focus group participants. Continuing with the trust and confidence theme, local government representatives in both regions perceived themselves to be generally trusted by the local communities which they represent. Thus we carried through to our field work with citizens, issues around trust in government and industry and the roles of local and national governments, furthering our exploration of the potential tensions between parties from a community perspective.

\section{Exploring community responses: CCS and the social license}

\subsection{Methodology}

In the second stage of this research, we conducted focus groups with members of the lay public in Lancashire and Teesside during November 2015. The Lancashire focus group was held in a scout hut in a residential area on the outskirts of Blackpool; the Teesside group met in a village hall in a small 
village immediately adjacent to the large industrial facilities at Wilton. Both focus group sites were close to industrial areas and to the coast. A professional company was employed to recruit participants resident in the specified areas (max 10 people per group, 8 individuals attended each group on the day), screening was performed to ensure no participants were: a) employed in the shale gas or CCS industry; b) a member of a campaigning group relating to shale gas or CCS or c) had previously participated in Focus Groups conducted by the research team; each participant received a $£ 40$ high street voucher. The format of each group was structured according to a common topic guide, which was designed to explore some of the themes that emerged during the stakeholder interviews with the lay participants. The project PI provided expertise in the form of two brief presentations, the first introducing the basics of CCS technology and the second focusing on storage and monitoring; during the second presentation monitoring data from $\mathrm{CO}_{2}$ storage projects, including Sleipner in Norway, was shown to the groups. Participants were given the opportunity to ask questions, following which the expert left the room for the remainder of the group discussions. More details on the Topic Guide content can be found in the supplementary material. In addition a set of statements were presented to the groups on wall charts as part of a voting exercise; participants were each given six 'sticky dots', one for each statement, and asked to place their dot along a line marked with four intervals between 'agree and 'disagree'. These statements, listed below, were based on themes that arose during the stakeholder interviews to explore the extent to which opinions voiced by stakeholders were also held by the focus group participants:

- I trust industry to manage $\mathrm{CO}_{2}$ storage

- Offshore storage of $\mathrm{CO}_{2}$ below the sea bed is a national not a local issue

- Regarding $\mathrm{CO}_{2}$ storage, I trust $L G$ to act in interest of communities

- CCS is a good way to address climate change

- Scientists know what happens to $\mathrm{CO}_{2}$ once it is stored

- The monitoring systems will ensure that $\mathrm{CO}_{2}$ storage is safe

In each group, the focus was on CCS, and specifically storage and monitoring, as required by the broader DiSSECS project objective and sensitive to the challenges encountered during the stakeholder interviews in relation to shale gas and potential public reactions. Where shale gas or fracking was raised spontaneously by focus group participants, facilitators supported those discussions but returned the focus back to CCS once those discussions had run their course. Each group lasted for 2 hours and was recorded, transcribed, and imported into Atlas.TI for thematic coding, by a minimum of two individual coders in order to ensure accuracy and lessen bias.

\subsection{Results}

At the beginning of each group an icebreaker question served to help participants to get to know each other, become comfortable talking about a familiar subject and provide the researchers with an indication of how participants viewed their local area. All of the Teesside participants described the area as a beautiful and picturesque place to live, but all also referred to industrial decline in the area. Lancashire participants described the area as a nice place to live, fairly quiet but with a lot of traffic.

The Lancashire Focus Group discussions were strongly influenced by previous, unanimously negative, experiences of the planning process for siting of a shale gas exploration site, wanting reassurance that 
CCS was a different technology. This group's initial responses to CCS were reflected in questions relating to the possible impacts and risk associated with storage and the possibility of leakage. In Teesside, the community was facing significant job losses due to the announcement of the closure of the steel works the preceding week and participants were focused on the benefits the technology might bring to the local economy and in particular maintaining employment in the area. Further, Teesside participants echoed the stakeholders' sense of pride in the region's industrial legacy, typically viewing CCS as an incremental technology applied to existing industrial activities. In the remainder of this section, we consider the responses of the focus group participants in more detail and, specifically, in the context of the key features of SLO outlined earlier (Section 2).

\subsubsection{The importance of scale}

Both groups discussed the scale of 'community' in the context of $\mathrm{CO}_{2}$ storage, who should be consulted and the need to ensure that consultation is genuine. Frustration in a current lack of, or inadequate, consultation around developments was expressed by members of both groups:

But again, it's just the meetings are there to show - even just pretend that they're actually putting these meetings out. [...] just - because nobody can prove that that's what was said at meetings, they just go ahead and do what they do anyway and say, "We did have these meetings" (Teesside R5)

In line with stakeholder responses, the Focus Group participants all thought that the debate around the management and use of offshore $\mathrm{CO}_{2}$ storage should be held at a national, rather than a local scale. Thus, the Teesside residents may not identify themselves as the host community for offshore $\mathrm{CO}_{2}$ storage from a CCS project initiated in Teesside. Concerns regarding the subsurface also differed depending on whether the storage and monitoring of $\mathrm{CO}_{2}$ was implemented onshore or offshore; in these groups a clear preference for offshore storage in the UK context was expressed, particularly as it is a small densely populated country. The expert had referred to the Aquistore project in Canada as an example of a commercial application of CCS, so participants were contrasting what a similar scale of project might mean in the UK. Any concerns expressed around leakage of storage were alleviated during a question and answer session with the expert.

In Teesside, there was a discussion around potential for storage of $\mathrm{CO}_{2}$ from other countries, linking back to considerations of who pays, who benefits, and $\mathrm{CO}_{2}$ being considered as a waste product.

Is it going to be all the power stations that we have that are going to be using it within the UK-or in Europe? And are there going to be other countries using it rather than just the European countries. Is it going to be, I don't know, shipped over from America or wherever, are they going to be using our facilities to inject it under the sea (...) So hopefully it's going to be a UK thing rather than a Europe because Europe can go and stick it in their own sea (Teesside R4)

Both groups spontaneously raised the potential impact of natural earthquakes on the integrity of storage reservoirs. No-one raised concerns about the potential for $\mathrm{CO}_{2}$ storage to induce seismicity, although this was discussed during the course of the expert question and answer sessions. During this discussion, the expert described $\mathrm{CO}_{2}$ storage as the "opposite of fracking", since hydraulic fracturing uses an increase in pressure to break open the rock to release gas, in contrast to $\mathrm{CO}_{2}$ storage where the aim is to maintain the integrity of the formation and ensure that there is no fracturing of the caprock. 


\subsubsection{Stakeholder relationships}

Both Focus Groups discussed the interplay between communities, government and industry. In Lancashire, referring to the recent shale gas controversy, participants felt that the council had not listened to communities initially, they perceived there to be a lack of response to community opposition until protest reached a certain point at which it could no longer be ignored:

People said no and they still went ahead and then once the protests started picking up and then it got to a point that I think they kind of realised, "Maybe we should find some way of saying no" (Lancashire R8)

Perceptions of "who pays for" and "who benefits from" these technologies was another recurring theme in discussions, with costs and benefits expressed in both financial terms as well as in terms of risks and wider impacts, and whether projects may lead to longer term investment in a region's industrial economy. Furthermore, in Lancashire, there was a sentiment that the industry and government were not interested in the concerns of the local community and their views of the technology, rather that they focused on financial profit, with a perceived disconnection from environmental issues in particular. Participants in the Teesside group clearly recognised the tradeoffs involved with hosting the heavy industries in their local area, understanding that they are participating in a social exchange. Nevertheless, there remains a delicate balance between achieving a situation in which residents identify the potential for a project to provide a variety of mutual benefits to communities and industry and one which prompts scepticism towards compensation schemes and erodes the social license, as expressed specifically in the context of fracking in Lancashire and illustrated in the following quotes:

Who's paying for that and will the profits be invested back into the [community].Or will it be back into the design to make things better? (Teesside R2)

I think for years we've all moaned about the area that we live in because of the industry around us and we all know ten minutes up the road we've got beautiful countryside, but we've moaned about it for years but we'd have it back if all them men could have their jobs back. We've moaned about it, but it kept men in jobs. I take my mam to Asda and she moans every time, "Look at that muck coming out of that chimney." Every time without fail. And I'm saying to her, "They've kept men in jobs" (Teesside R4)

Everywhere there's a well for fracking, they are going to give us one of these places (community centre) for the thing, and then every so much stuff they bring out there was a premium for the local community. It was a bribe. It was an actual bribe. (Lancashire R2)

...they're not doing it for us, fracking. Any oil or gas, they are doing it for profit. It's wonderful but are they bothered about us, are they bothered about what environment damage they do? They are just making money, millions and millions of pounds of money. (Lancashore R2)

\subsubsection{SLO as a dynamic condition}

A critical factor in how conditions for achieving an SLO may change over time is how experiences with other technologies or projects influence perceptions. This was particularly evident in the Lancashire group, where recent applications for licenses to explore for shale gas had been highly controversial. When fracking was raised in this group it was in the context of how the council handled and responded to the planning applications but the potential impacts of $\mathrm{CO}_{2}$ storage were also evaluated with reference to experiences with fracking: 
(...) persuading the general public that there would be no pollution of the ocean like fracking is polluting the water system. They keep saying it doesn't, but we have had earthquakes through fracking here in Blackpool, we've had two earthquakes caused by fracking, that's why fracking has to stop in my view (Lancashire, R2)

Past experience of previous technologies influenced participants' opinions of new technology. Once trust is breached and SLO shifts it can be difficult to rebuild, even when considering deployment of a different technology. Both groups sought reassurance that CCS was different to fracking:

I'll be honest, when I first came I thought [...]l was going to very opinionated about fracking and things, I thought that's what this was going to be about and I was going to be rather annoyed at times. But it really isn't. [...] so straight away in my head alarm bells rang as if to say this is going to have something to do with something that's not going to be what we want to see. But that sounds the total opposite (Teesside, R5)

So if you have to judge something by the fact that they allowed them to dig up and to do all the rest against the wishes of people, I suppose they may have lost the backing of a lot of people and respect may have diminished for them. So with different things, you might assume that they will act the same way again (Lancashire R8)

\subsubsection{Risk, trust and confidence}

Discussion in Teesside revealed a delicate balance whereby, despite living with and depending on large industrial installations, the underlying awareness of associated risks was ever present, even though there had been no major incidents in the area. With the local area dominated by a cluster of process industries, when the group discussed risk in the context of CCS, the emphasis was on potential industrial and health risks that may be associated with capture rather than concerns relating to offshore storage, which were seen as being more remote. The notion of a "ticking time bomb", something ominous in the background, was followed up in discussions around perceptions of higher incidents of cancer in the area, risks related back to local industrial processes:

Because we've sat on this time bomb since the forties and nothing has ever gone wrong (Teesside R4)

I know loads of people who've died of cancer and they're all round about the same age and they all worked onsite and what have you (Teesside R1)

In contrast, the Lancashire group did not raise issues relating to capture, the focus remained on storage throughout., Both focus groups articulated a greater level of trust in industry than in local government to manage $\mathrm{CO}_{2}$ storage, typically expressing confidence in their technical competence, supporting the views expressed by the professional stakeholders. These views also emerged within a voting exercise, presented in Figures 1 and 2. The strong trust in industry from respondents in Teesside can be clearly seen, whereas Lancashire respondents gave a more mixed response. 


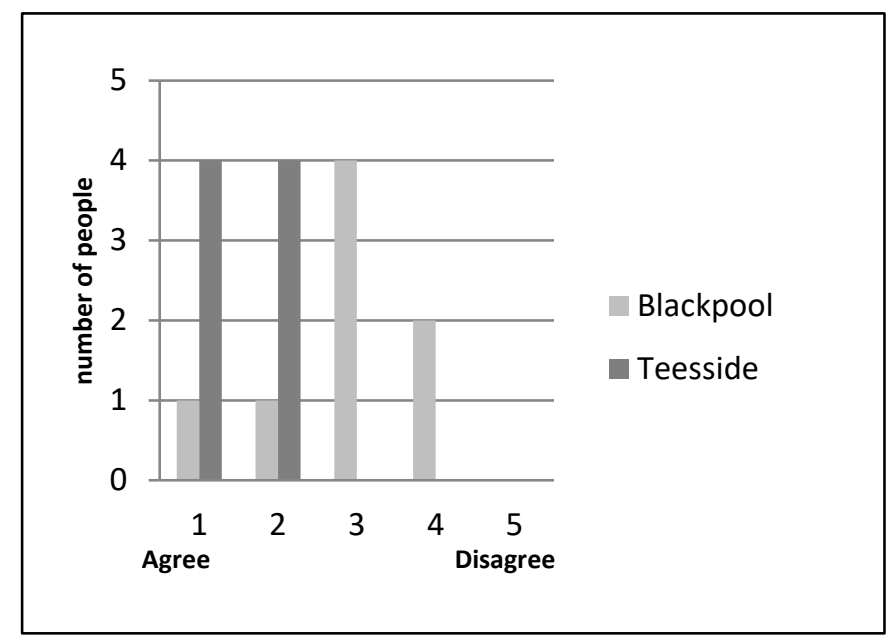

Figure 1: Focus group responses: "I trust industry to manage $\mathrm{CO}_{2}$ storage"

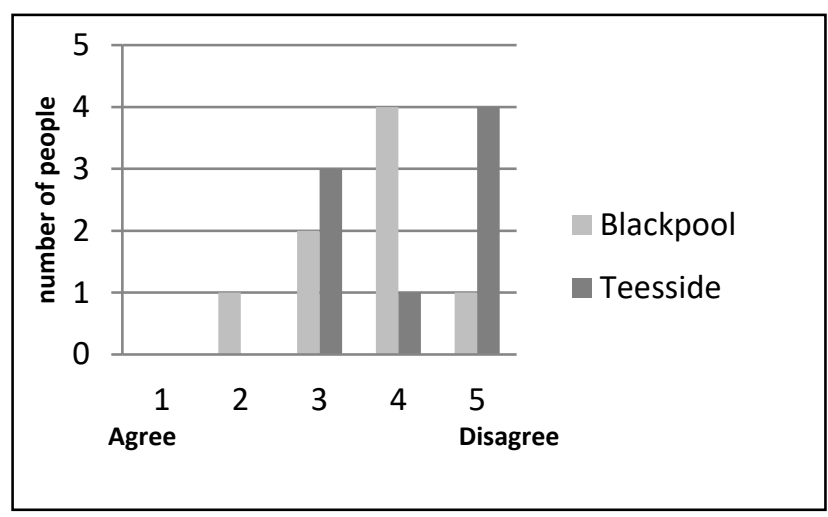

Figure 2: Focus group responses: "Regarding $\mathrm{CO}_{2}$ storage, I trust Local Government to act in interest of communities"

In Teesside, an area dominated by heavy industry, this trust was associated with a pride in the area's industrial legacy and history of technical innovation. This was expressed by both the professional stakeholders and focus group participants alike, citing the region's pioneering role from being the birthplace of commercial railways, a place where steelworks became the 'backbone' of the area (stakeholder interviews, NGO) to its role in developing safety standards (focus group); there was a recognition that "dangerous stuff happens here" (stakeholder interviews, local councillor) with the associated expertise to manage such processes, making it a good place to locate a technology such as CCS:

Most of the regulations regarding dangerous processes and movement of materials or whatever all were created here on Teesside, all in Teesside. All the safety things that you find in the industry today, they were created here in Teesside, there's no question about it (Teesside R3)

...it's just got a lot better under private management. And they know what they're doing, there's people in national government haven't got a clue what they're doing. So you've got to put your trust in the industry because if you didn't you'd never get anywhere. [...] they're the people who are going to be doing it, so they've got the technology and the skills (Teesside R4)

But, just as trust can be built up over many years of industrial heritage, the Lancashire groups revealed that the experiences with fracking appear to have made participants more sceptical: 
But it's always a safety issue because they said when they were doing the fracking there would be no problems, they kept on and on doing it and obviously there were problems then, so it's if they are truthful. (Lancashire R4)

The stated trust in industry remained conditional and, to an extent, highly contingent. Distrust for the local government was prominent at both locations, in contrast to how the local government representatives perceive their standing in the community; this distrust in government was expressed at both national and local levels:

Yeah. Not only that, I wouldn't trust the local governments to make me a cup of tea (Teesside R4)

...the government will probably hush-hush everything up if any accidents happen (Teesside R2)

Specifically in relation to the operation and management of storage sites and monitoring, participants to both groups expressed confidence in the scientists and their tools. Asked about who should be responsible for choosing and managing storage sites there was a clear preference for independent experts, such as scientists, rather than government to be involved:

You can't put the fox in charge of the hen coop, that's what you're going to do if you leave it to the government (Teesside R3)

A critical element of the consultation process for CCS projects, which have a significant technical dimension and limited familiarity across the general public, relates to how the key features of the implementation and future management of projects are communicated. Both groups demonstrated how an intermediary from within the community can support exchanges between experts and communities in building up understanding. In each of our two groups, as the expert explained technical information about $\mathrm{CCS}, \mathrm{CO}_{2}$ storage and its monitoring, there were one or two individuals who took on this role. Although they were not previously familiar with CCS technology, these members of the groups, who were comfortable discussing technical matters, were more confident in asking questions and played a role in helping other participants to understand and engage in discussions. This 'intermediation' role was explicitly identified and welcomed by participants to groups in both of the two locations.

\section{Discussion}

This research set out to explore the social context for $\mathrm{CO}_{2}$ storage in the UK, possible responses to underground $\mathrm{CO}_{2}$ storage, and significant factors in establishing a social license in the context of CCS and in particular offshore $\mathrm{CO}_{2}$ storage in the UK. The method does not attempt to predict how the introduction of CCS in the two study areas, or beyond, would be received and the results do not present the view of a statistically representative sample. The small sample of qualitative data presented here is designed to explore in more detail the underlying reasoning behind how certain views may form. By understanding the social context within two case study regions, a nuanced assessment can be made of the social processes associated with establishing a social license for CCS and $\mathrm{CO}_{2}$ storage projects. Returning to the key features of the SLO - scale, stakeholder relationships, the dynamic nature of the SLO and issues of trust, risk and confidence, in this section we consider the interrelationships between different stakeholders, including lay publics, and their role in an SLO for $\mathrm{CO}_{2}$ storage. 
Scale cuts across many aspects of the social license, whether in terms of responses from local communities hosting a project, broader national concerns about the deployment of a particular technology or with respect to governance and policy objectives at national and local levels. The discussions both with stakeholders and within focus groups highlighted the importance of local communities, each with their own specific sense of place and social identity, and the relationship between communities, government and industrial actors at different scales. In some instances this reveals tensions in the governance processes and a challenge facing local government when obligations to the local communities which they represent and to higher levels of government are in conflict. The importance of scale is further apparent with respect to the industrial partners aiming to implement a proposed project - whether they are perceived as 'local', with a history and relationship with the local community, or as 'outsiders' lacking a social presence or perceived responsibility in the area. The research highlighted how for offshore storage specifically, there is no local affected community as such but instead there exists a broader community of interest, including diverse stakeholder groups. Thus, the scale at which an SLO is considered is different in our two technology examples but it may also change over time and for different aspects of a project; an SLO for a CCS project encompassing capture, transport and storage requires consideration at different scales for different elements of the chain to be included.

The relationships between diverse stakeholders including industry, governments and local communities and, in turn, their position with respect to the technology is critical to the SLO. In Lancashire, clear tensions could be seen between national and local government and their different mandates and policy objectives. Local government stakeholders are caught between national government, seeking to implement technology deployment to meet energy policy objectives, and the need to comply with local scale policies, and with the possibility that many local residents may oppose deployment. Ultimately, frustration and lack of agency has led to a breach of the trust between communities and local government, and between local and national government, raising issues of responsibility and agency (Bickerstaff et al., 2008) with, as a consequence in the case of fracking, a failure to establish an SLO.

In Teesside, however, the possibility of a tentative opportunity for 'co-ownership' is raised in the context of CCS; the technology has the potential to be deployed by industries, such as the chemical industry, that share a long history with the local community, and where there is a level of social trust. This trust, however, is fragile; the community is very aware of their dependence on the industry and the risks that they bear in exchange for local employment in an area affected by high levels of poverty. This situation contrasts with that of Lancashire, where there is no connection established between either shale gas or CCS industries. Here, any potential social exchange is viewed with scepticism, the community is less willing to accept potential risks, and compensation or benefits are identified as 'bribes'; research elsewhere has explored the complex relationship between different types of compensation and attitudes to risk within host communities (ter Mors et al, 2012).

The benefits of introducing a technology such as CCS in an area with a longstanding association with related industrial networks may be realised across many layers of the governance process. As well as matters of reputation and relationships with individuals, communities and institutions, this familiarity with the sector can bring regulatory know-how to a region. In a study using regulation of hydraulic fracturing as an analogous technology for onshore $\mathrm{CO}_{2}$ storage in the US, Herzog and Wolff (2014) found that areas with established experience in the oil and gas industry developed 'more sustainable 
and predictable' regulatory regimes. Past experience with both the initial implementation and subsequent proposals for further use of hydraulic fracturing framed the way in which Lancashire respondents evaluated future technology applications and the associated regulatory and governance processes. Residents in Lancashire evaluated the unfamiliar technology of CCS relative to their experiences with fracking.

Thus familiarity may influence judgements of trust and accountability both positively and negatively; greater familiarity raises the consciousness of an organisation, technology or process, bringing it to the forefront of people's thoughts (Sinclair and Miller, 2010). Both groups evaluated the unfamiliar technology of CCS relative to their own experience of other technologies, so in Lancashire participants reflected in how $\mathrm{CO}_{2}$ storage might be similar or different to fracking and in Teesside participants focused more on the capture aspects of CCS. It is well documented that familiarity may increase tolerance to risk, enabling individuals to 'calibrate' their judgements of a situation (e.g. Renn, 1998); when individuals do not have the expertise to assess levels of risk for themselves, their response will depend on their trust in the organisations associated with or communicating a proposed development and hence the credibility with which they view any information provided (Zimmer et al., 2009). In the case of fracking, neither the technology nor the companies are established in the Lancashire region perceptions are based on a sudden flurry activity around planning applications for an industrial process which is perceived as novel, any familiarity with it has come through controversies reported in other regions (e.g. in the UK and in North America) and proposed by companies not associated with previous 'benign' activities. In the case of CCS, despite the lack of knowledge of technology per se, there are many ways in which necessary trust and familiarity is manifested to lay the foundations on which a SLO might be built. The industries involved are well established in the region and the infrastructure required for the technology is familiar - Teesside maybe uniquely well placed in this way as a location for early demonstration of CCS in the UK. In this way we suggest that for early demonstration projects, an SLO may be specific to a particular project, associated with particular stakeholders and social context rather than with CCS technology itself. As experience with the technology grows, and the number of successful projects increases, this may consolidate a SLO which grows around the technology as becomes more widely adopted.

Teesside participants identified with and were proud of the industrial heritage combined with a recognition of the economic importance of industry for the communities. This region is by necessity evolving and responding to the economic challenges it is facing, whilst wanting to maintain an industrial base and build on their reputation as engineering pioneers. This is a shift from the 'spoiled identity' and social stigma around Teesside described in Bush et al. (2001); our participants saw CCS as a technology that could be part of the cleaning up process, both at a local scale, but also from a national and global climate change perspective. Indeed, the findings support those of Venables et al (2012) as to how a sense of place can mediate (but not moderate) perceptions of risk.

Translating scientific evidence was a key factor in these early stages of the CCS SLO in both regions. The focus groups benefitted from the input of a geologist from the project to introduce CCS technology, $\mathrm{CO}_{2}$ storage and to answer questions from the participants. The geologist represented the face of the monitoring and storage processes and conveyed a friendly and open demeanour, participants asked questions freely, mediated in part by other group members who felt most confident in discussing technical topics. Although our findings relate to a research-focused context, good 
community relations built up from outset by the Aquistore project in Canada (the first operational commercial scale CCS plant) suggest that there is no reason why this openness to participate should not be equally possible in a commercial setting. An early and extensive outreach programme organised by the developers found that building relationships throughout the local community with residents and stakeholders, via so-called 'kitchen table' meetings and open houses at the plant, enabled the developers to "gain local contacts and champions within the community" (Young and Sacuta, 2014).

Given the lack of familiarity of participants with $\mathrm{CO}_{2}$ storage, the confidence that they expressed in the monitoring and regulation of storage reservoirs demonstrated their social trust, firstly in those presenting the information on storage but also in a familiar industry for the operation of CCS plants (Siegrist and Cvetovich, 2000).

\section{Conclusions}

CCS is a key climate change mitigation technology, and one that will need to be deployed at a large scale to meet the commitments made within the Paris Agreement. In this paper, and with this challenge in mind, we consider the social responses to low energy infrastructure in ways that go beyond 'acceptance of' or 'support for' a particular technology, and adopt a social license to operate framework. By focusing upon both fracking for shale gas and CCS, we compare two technologies which share some similarities in terms of operational procedures, but which are at different stages of deployment. In the UK, fracking has proved a controversial technology, where industry has failed to obtain a social license; in contrast CCS has yet to be deployed and remains a technology mostly unknown to the majority of the population. From our empirical research relating to industrial CCS in Teesside, the industry appears to be well placed to establish a social license for CCS; it has a strong foundation in the community and a degree of trust and familiarity is already established. However, as CCS is a technology with elements that can be geographically distant from each other, the scale of an SLO is key and, when storage is offshore, there may not be an obvious host community, making it harder to establish longstanding relationships.

Our findings demonstrated that a problem remained regarding procedural justice and the governance process. Concerns were raised, particularly in relation to fracking, about the broader democratic processes connected to industrial planning; communities reported feeling less empowered in the decision making process, when national strategies can lead to an overturning of local decisions, and in the context of a changing role for local councils. Perceptions of trust in the competence and motivations of key institutions are critical and are dependent on the track record of those institutions in managing industrial processes as well as past experiences with different technologies. Both the regional and national stakeholders in this study expressed a keen awareness of the long term impact on perceptions of a technology, such as fracking, that has become tarnished by high profile controversy. Past experience of previous technologies may influence participants' opinions of other new technologies; once trust is breached and SLO shifts, it can be difficult to rebuild, with the effects potentially spilling over to influence responses in the context of a different technology. The foundation for establishing a social license for CCS appears to be in place but consolidating and maintaining support for CCS depends on the evolving social, industrial and political landscape. We conclude with eight principles which may help to support a social license for CCS: 
1. Understand the social context: what is the area like? What is there now, what was there before, who lives there, what they do, what has happened there, how and why did it happen? Noting that the "area" could be a place and area, a corridor, a region, a country and different areas may be relevant within a single project.

2. Develop key arguments in context: successful key arguments for CCS will depend on the social context, for example these may focus on potential economic benefits arguments framed in terms of investment, employment and leadership opportunities and the possible benefits that CCS might bring alongside reductions in greenhouse gas emissions necessary to maintain key industrial activities.

3. Foster stakeholder networks: establishing a relationship between stakeholders that is based on trust is a long term process dependent on the interactions of a variety of factors, including: current and past associations which build confidence, a reputation for reliability and predictability, and expectations of how the institutions will operate.

4. Grow offline communication networks: the interaction between key stakeholders, active within offline networks, and the press is central to how press coverage influences opinions on the technology within civil society. Local and regional networks may be insufficient to influence national policies, whether for support moderation of technologies.

5. Establish online communication networks: CCS does not yet have an identify on social media outside limited niche network; for this presence to extend into wider online communities it must build a unique identity associated with the "CCS" acronym.

6. Build trust and confidence: perceptions of risk are influenced by trust and confidence in institutions and procedures; it takes years to demonstrate competence and integrity, once trust is lost it can damage prospects for an SLO for future proposals in other technologies.

7. Different social licenses at different scales: multiple SLOs may come in to play across different scales: successful deployment of a technology will require SLO at an appropriate scale, bearing in mind there may be conflict between the policy priorities at different scales.

8. Maintaining a SLO: a SLO should be treated as an ongoing process - it may be contingent on a variety related or unrelated events or factors which may impact the stability of an SLO once established.

\section{Acknowledgements}

This work was carried out within the DiSECCS project https://www.bgs.ac.uk/diseccs. DISECCS is funded by the Engineering and Physical Sciences Research Council (EPSRC) UK, Grant number $\mathrm{EP} / \mathrm{KO35878/1}$. We are indebted to all of the professional and lay participants to the empirical work presented here, and thank them for their time and contribution to the discussions. We would also like to thank Dr. Andy Chadwick for providing expert information and answering questions during the Focus Groups.

\section{References}

Ashworth, P., Bradbury, J., Wade, S., Ynke Feenstra, C.F.J., Greenberg, S., Hund, G., Mikunda, T., 2012. What's in store: Lessons from implementing CCS. International Journal of Greenhouse Gas Control 9, 402-409.

Bachmann, R., Inkpen, A.C., 2011. Understanding institutional-based trust building processes in interorganisational relationships. Organization Studies 32, 281-301.

Batel, S., Devine-Wright, P., Tangeland, T., 2013. Social acceptance of low carbon energy and associated infrastructures: A critical discussion. Energy Policy 58, 1-5. 
Bickerstaff, K., Simmons, P., Pidgeon, N., 2008. Constructing responsibilities for risk: negotiating citizen-state relationships. Environment and Planning A 40, 1312-1330.

Bradbury, J., Ray, I., Peterson, T., Wade, S., Wong-Parodi, G., Feldpausch, A., 2009. The Role of Social Factors in Shaping Public Perceptions of CCS: Results of Multi-State Focus Group Interviews in the U.S. Energy Procedia 1, 4665-4672.

Bush, J., Moffatt, S., Dunn, C., 2001. 'Even the birds round here cough':: stigma, air pollution and health in Teesside. Health \& Place 7, 47-56.

DECC, 2014. Fracking UK shale: understanding earthquake risk, in: Change, D.o.E.a.C. (Ed.), London. Dowd, A.-M., James, M., 2014. A Social Licence for Carbon Dioxide Capture and Storage: How Engineers and Managers Describe Community Relations. Social Epistemology 28, 364-384.

Dowd, A.-M., Rodriguez, M., Jeanneret, T., 2015. Social Science Insights for the BioCCS Industry. Energies 8, 4024-4042.

Earle, T., Siegrist, M., 2008. Trust, Confidence and Cooperation model: a framework for understanding the relation between trust and Risk Perception. International Journal of Global Environmental Issues 8.

Eurobarometer, 2011. Public Awareness and Acceptance of CO2 Capture and Storage. European Commission, Brussels.

Falcon-Suarez, I, North, L, Best, A I. Experimental rig to improve the geophysical and geomechanical understanding of $\mathrm{CO}_{2}$ reservoirs. 2014. Energy Procedia, 59, 75 81. http://dx.doi.org/10.1016/j.egypro.2014.10.351

Feenstra, C.F.J., Mikunda, T., Brunsting, S., 2010. What happened in Barendrecht? case study on the planned onshore carbon dioxide storage in Barendrecht, the Netherlands. CSIRO.

Fontana, A., Frey, J.H., 2000. The Interview: from structured questions to negotiated text, in: Densin, N.K., Lincoln, Y.S. (Eds.), The SAGE Handbook of Qualitative Research, 2 ed. Sage Handbooks, Thousand Oaks, California, pp. 645-672.

Gehman, J., Thompson, D., Alessi, D., Allen, D., Goss, G., 2016. Comparative Analysis of Hydraulic Fracturing Wastewater Practices in Unconventional Shale Development: Newspaper Coverage of Stakeholder Concerns and Social License to Operate. Sustainability 8, 912.

Gough, C., O'Keefe, L., Mander, S., 2014. Public perceptions of CO2 transportation in pipelines. Energy Policy 70, 106-114.

Hall, N., Lacey, J., Carr-Cornish, S., Dowd, A.-M., 2015. Social licence to operate: understanding how a concept has been translated into practice in energy industries. Journal of Cleaner Production 86, 301310.

Hay, I., 2010. Qualitative Research Methods in Human Geography. Oxford University Press Canada Herzog, H., Wolff, J., 2014. What lessons can hydraulic fracturing teach CCS about social acceptance? Energy Procedia 63, 7024-7042.

House, E.J., 2013. Fractured fairytales: the failed social license for unconventional oil and gas development. Wyoming Law Review 13.

Itaoka, K., Dowd, A.-M., Saito, A., Paukovic, M., de Best-Waldhober, M., Ashworth, P., 2013. Relating Individual Perceptions of Carbon Dioxide to Perceptions of CCS: An International Comparative Study. Energy Procedia 37, 7436-7443.

Jenkins, C., Chadwick, R. A., \& Hovorka S. J., 2015. The state of the art in monitoring and verification ten years on. IPCC Special Report: 10th Anniversary Issue. International Journal of Greenhouse Gas Control, 40, 312-349 10.1016/j.ijggc.2014.09.010.

Joffe, H., 2003. Risk: From perception to social representation. British Journal of Social Psychology 42. Lancashire County Council, 2011. Employment and Economic Activity "2011 Census", http://www.lancashire.gov.uk/lancashire-insight/economy/employment-and-economic-activity-

2011-census/employment-by-industry-sector.aspx. accessed 10/11/2016

Lancashire County Council, 2016a. Lancashire Insight, key statistics. http://www.lancashire.gov.uk/lancashire-insight/. Accessed 10/11/2016 
Lancashire County Council, 2016b. Shale gas developments in Lancashire, web page accessed 15 June 2016, http://www.lancashire.gov.uk/council/planning/major-planning-applications/shale-gasdevelopments-in-lancashire.aspx

L'Orange Seigo, S., Dohle, S., Siegrist, M., 2014. Public perception of carbon capture and storage (CCS): A review. Renewable and Sustainable Energy Reviews 38, 848-863.

Mabon, L., Vercelli, S., Shackley, S., Anderlucci, J., Battisti, N., Franzese, C., Boot, K., 2013. 'Tell me what you Think about the Geological Storage of Carbon Dioxide': Towards a Fuller Understanding of Public Perceptions of CCS. Energy Procedia 37, 7444-7453.

Mabon, L., Shackley, S., Bower-Bir, N., 2014a. Perceptions of sub-seabed carbon dioxide storage in Scotland and implications for policy: A qualitative study. Marine Policy 45, 9-15.

Mabon, L., Shackley, S., Blackford, J.C., Stahl, H., Miller, A., 2014b. Local perceptions of the QICS experimental offshore $\mathrm{CO} 2$ release: Results from social science research. International Journal of Greenhouse Gas Control, 38, 18-25

Mander, S., Polson, D., Roberts, T., Curtis, A., 2010. Risk from $\mathrm{CO}_{2}$ storage in saline aquifers: a comparison of lay and expert perceptions of risk. Energy Procedia 4, 6360-6367.

Sarah Mander, Rebecca Cunningham, Louise Lever, Clair Gough, 2017, Comparing online and offline knowledge networks of Carbon Capture and Storage, Energy Procedia, In press.

Midden, C.J.H., Huijts, N., 2009. The role of trust in the affective evaluation of novel risks: the case of $\mathrm{CO}_{2}$ storage. Risk Analysis 29, 743-751.

Moffat, K., Zhang, A., 2014. The paths to social licence to operate: An integrative model explaining community acceptance of mining. Resources Policy 39, 61-70.

Moffat, K., Lacey, J., Zhang, A., Leipold, S., 2015. The social licence to operate: a critical review. Forestry $0,1-12$.

Oltra, C., Sala, R., Solà, R., Di Masso, M., Rowe, G., 2010. Lay perceptions of carbon capture and storage technology. International Journal of Greenhouse Gas Control 4, 698-706.

Oltra, C., Upham, P., Riesch, H., Boso, À., Brunsting, S., Dütschke, E., Lis, A., 2012. Public Responses to $\mathrm{CO}_{2}$ Storage Sites: Lessons from Five European Cases. Energy \& Environment 23, 227-248.

Papageorgiou, G \& Chapman, M. 2015. Multi-fluid squirt flow and Hysteresis Effects on the Bulk Modulus-Water Saturation relationship. Geophysical Journal International. 203.2, 814817. http://gji.oxfordjournals.org/content/203/2/814.short

Parsons, R., Moffat, K., 2014. Constructing the Meaning of Social Licence. Social Epistemology 28, 340363.

de Pater, C.J., Baisch, S., 2011. Geomechanical Study of Bowland Shale Seismicity, Synthesis Report. Cuadrilla Resources.

Poortinga, W., Pidgeon, N., 2005. Trust in Risk Regulation: Cause or consequence of the Acceptability of GM food? Risk Analysis 25, 199-209.

Raman, S., Mohr, A., 2014. A Social Licence for Science: Capturing the Public or Co-Constructing Research? Social Epistemology 28, 258-276.

Reiner, D.M., 2016. Learning through a portfolio of carbon capture and storage demonstration projects. Nature Energy 1, 15011.

Renn, O., 1998. The role of risk perception for risk management. Reliability Engineering \& System Safety 59, 49-62.

Schlosberg, D., 2013. Theorising environmental justice: the expanding sphere of a discourse, Environmental Politics, 22:1, 37-55, DOI: 10.1080/09644016.2013.755387

Shrader-Frechette, K. (2002) Environmental Justice: Creating Equality, Reclaiming Democracy (Oxford University Press, New York).

Siegrist, M., Cvetovich, G., 2000. Perception of hazards: the role of social trust. Risk Analysis 20, 713719. 
Sinclair, J. and Miller, B., Understanding public response to advocacy campaigns: a persuasion knowledge approach, in: Kahlor, L, and Stout P. (Eds.) Understanding and communicating science: new agendas in communication, Routledge, New York

Slovic, P., 1993. Perceived risk, trust and democracy. Risk Analysis 13, 675-682.

Smith, D.C., Richards, J.M., 2015. Social License to Operate: hydraulic fracturing-related challenges facing the oil \& gas industry. Oil and Gas, Natural Resources, and Energy Journal 81.

Steeper, T., 2013. CO2CRC Otway Project Social Research: Assessing CCS Community Consultation. Energy Procedia 37, 7454-7461.

Syn, J., 2014. The Social License: Empowering Communities and a Better Way Forward. Social Epistemology 28, 318-339.

Tees Valley Unlimited, 2016. Tees Valley Economic Assessment 2015/2016. https://teesvalleyca.gov.uk/wp-content/uploads/2016/03/tees valley economic assessment 2015 full.pdf. Accessed $\underline{10 / 112016}$

ter Mors, E., Terwel, B.W., Daamen, D.D.L., 2012. The potential of host community compensation in facility siting. International Journal of Greenhouse Gas Control 11, S130-S138.

Terwel, B.W., Harinck, F., Ellemers, N., Daamen, D.D.L., 2011. Going beyond the properties of CO2 capture and storage (CCS) technology: How trust in stakeholders affects public acceptance of CCS. International Journal of Greenhouse Gas Control 5, 181-188.

Thomson, I., and R. Boutilier, 2011. The social licence to operate, in: Darling, P. (Ed.), SME mining engineering handbook, 3rd ed. Society for Mining, Metallurgy, and Exploration, Littleton, Colorado, pp. 673-690.

TVCA, 2016. https://teesvalley-ca.gov.uk/about-the-area/location/ Accessed 10/112016

UNFCCC, 2015. The Paris Agreement, UNFCCC/CP/2015/L.9. United Nations Framework Convention on Climate Change.

Upham, P., Roberts, T., 2011. Public perceptions of CCS: emergent themes in pan-European focus groups and implications for communications. International Journal of Greenhouse Gas Control 5, 1359-1367.

Venables, D., Pidgeon, N.F., Parkhill, K.A., Henwood, K.L., Simmons, P., 2012. Living with nuclear power: Sense of place, proximity, and risk perceptions in local host communities. Journal of Environmental Psychology 32, 371-383.

Wallquist, L., L'Orange-Seigo, S., Visschers, V.H.M., Siegrist, M., 2012. Public acceptance of CCS system elements: A conjoint measurement. International Journal of Greenhouse Gas Control 6, 77-83.

Wallquist, L., Visschers, V.H.M., Siegrist, M., 2010. Impact of knowledge and misconceptions on benefit and risk perception of CCS. Environmental Science and Technology 44, 6557-6562.

Whitton, J., Brasier, K., Charnley-Parry, I., Cotton, M., 2017. Shale gas governance in the United Kingdom and the United States: Opportunities for public participation and the implications for social justice. Energy Research \& Social Science 26, 11-22.

Yang, L., Zhang, X., McAlinden, K.J., 2016. The effect of trust on people's acceptance of CCS (carbon capture and storage) technologies: Evidence from a survey in the People's Republic of China. Energy 96, 69-79.

Young, A., Sacuta, N., 2014. Farmers, Open houses, and Technical Knowledge: Public Outreach in Aquistore. Energy Procedia 63, 7043-7046.

Zhang, A., Moffat, K., 2015. A balancing act: The role of benefits, impacts and confidence in governance in predicting acceptance of mining in Australia. Resources Policy 44, 25-34.

Zimmer, R., Zschiesche, M. and Hölzinger, N., 2009. The role of trust and familiarity in risk communication, $3^{\text {rd }}$ International Conference on Hydrogen Safety, Ajaccio, France 


\section{Figure Captions}

Figure 2: Focus group responses: "I trust industry to manage $\mathrm{CO}_{2}$ storage"

Figure 2: Focus group responses: "Regarding $\mathrm{CO}_{2}$ storage, I trust Local Government to act in interest of communities" 